Research report

\title{
Obsessive-compulsive symptom dimensions in the general population: Results from an epidemiological study in six European countries
}

\author{
M.A. Fullana ${ }^{\text {a,b,* }}$, G. Vilagut ${ }^{\text {c,d }}$, S. Rojas-Farreras ${ }^{c}$, D. Mataix-Cols ${ }^{\text {b }}$, R. de Graaf ${ }^{\text {, }}$ \\ K. Demyttenaere ${ }^{\mathrm{f}}$, J.M. Haro ${ }^{\text {g,h }}$, G. de Girolamo ${ }^{\mathrm{i}}$, J.P. Lépine ${ }^{\mathrm{j}}$, H. Matschinger $^{\mathrm{k}}$, J. Alonso ${ }^{\text {c,d }}$ \\ and for the ESEMeD/MHEDEA 2000 investigators $^{1}$
}

a Anxiety Unit, IAPS, Hospital del Mar and Department of Psychiatry, Autonomous University of Barcelona, Barcelona, Spain

b Division of Psychological Medicine, Institute of Psychiatry, King's College London, London, United Kingdom

${ }^{c}$ Mental Health Services Research Unit (IMIM-Hospital del Mar), Barcelona, Spain

d CIBER en Epidemiología y Salud Pública (CIBERESP), Spain

e Netherlands Institute of Mental Health and Addiction, Trimbos-instituut, Utrech, The Netherlands

${ }^{\mathrm{f}}$ Department of Neurosciences and Psychiatry, University Hospital Gasthuisberg, Leuven, Belgium

${ }^{g}$ Fundació Sant Joan de Déu, Mental Health Services, Sant Boi de Llobregat, Barcelona, Spain

${ }^{\mathrm{h}}$ CIBER en Salud Mental (CIBERSAM), Spain

i IRCCS Centro S. Giovanni di Dio Fatebenefratelli, Brescia, Italy

${ }^{j}$ Institut National de la Santé et de la Recherche Médicale, Paris, France

${ }^{\mathrm{k}}$ Department of Psychiatry, University of Leipzig, Germany

\section{A R T I C L E I N F O}

\section{Article history:}

Received 17 July 2009

Received in revised form 3 November 2009

Accepted 30 November 2009

Available online 21 December 2009

\section{Keywords:}

Obsessive-compulsive disorder

Anxiety disorders

Epidemiology

\begin{abstract}
A B S T R A C T
Background: The prevalence of obsessive-compulsive symptom dimensions and their sociodemographic and psychopathological correlates at the population level are unknown. Method: Obsessive-compulsive symptom dimensions and mental disorders were assessed with the Composite International Diagnostic Interview 3.0 in a random subsample $(n=2804)$ of individuals participating in a cross-sectional survey of the adult general population of six European countries. Results: The lifetime prevalence of any obsessive-compulsive symptom dimension was $13 \%$. Harm/ Checking was the most prevalent dimension (8\%) followed by Somatic obsessions (5\%) and Symmetry/Ordering (3\%). Females were more likely to have symptoms in Contamination/Cleaning $(\mathrm{OR}=3,95 \% \mathrm{CI}=1.06-8.51)$ and Somatic obsessions $(\mathrm{OR}=1.88,95 \% \mathrm{Cl}=1.05-3.37)$. All symptom dimensions were associated with an increased risk of most mental (but not physical) disorders. There were some differences in prevalence between countries.

Limitations: The interference associated with each symptom dimension could not be assessed. Few direct data are available on the validity of the CIDI to assess obsessive-compulsive symptom dimensions.

Conclusions: Obsessive-compulsive symptom dimensions are relatively frequent in the general population. Their sociodemographic and psychopathological correlates may be slightly different in clinical and community samples. They are associated with an increased risk of most mental disorders.
\end{abstract}

(c) 2009 Elsevier B.V. All rights reserved.

\footnotetext{
* Corresponding author. King's College London, Institute of Psychiatry, PO69 De Crespigny Park Rd., London SE5 8AF, United Kingdom. Tel.: + 44 207 8480543 ; fax: +442078480379 .

E-mail address: Miguel.Fullana@iop.kcl.ac.uk (M.A. Fullana).

${ }^{1}$ The ESEMeD/MHEDEA 2000 Investigators are: Jordi Alonso, Matthias Angermeyer, Herbert Matschinger, Ronny Bruffaerts, Traolach S. Brugha, Giovanni de Girolamo, Ron de Graaf, Koen Demyttenaere, Isabelle Gasquet; Josep Maria Haro, Steven J. Katz; Ronald C. Kessler, Viviane Kovess, Jean Pierre Lépine, Johan Ormel, Gabriella Polidori, and Gemma Vilagut.
} 


\section{Introduction}

Obsessive-compulsive disorder (OCD) is a disabling mental disorder characterised by the presence of intrusive thoughts, images or impulses that cause anxiety (obsessions) and/or the presence of repetitive overt or covert actions that are carried out to decrease anxiety (compulsions) (American Psychiatric Association, 1994). For a person to meet full diagnostic criteria, the symptoms must be frequent and sufficiently interfering.

The lifetime prevalence of $O C D$ in the general population is estimated to be in the region of $1-2 \%$ (Fontenelle et al., 2006; Ruscio et al., 2008). However, obsessive-compulsive (OC) symptoms may be much more prevalent in the general population (e.g. Grabe et al., 2000; Ruscio et al., 2008) than full-blown OCD is. These sub-syndromal symptoms have received little attention but several studies have shown that they are associated with moderate degrees of interference and increased psychiatric morbidity (Fullana et al., 2009; Grabe et al., 2000, 2001; Ruscio et al., 2008). Perhaps more importantly, there is longitudinal evidence that sub-syndromal levels of OC symptoms in childhood increase the risk of full-blown OCD in adulthood (Fullana et al., 2009). These findings underscore the importance of adopting a dimensional approach to OCD. It is possible that the early identification and treatment of sub-syndromal cases may lead to reduced risk for OCD.

The content of $\mathrm{OC}$ symptoms is heterogeneous and two patients with OCD may have very different clinical presentations. Factor and cluster analytical studies of measures of OC symptoms in clinical samples have identified some symptom dimensions that summarise this complex clinical presentation. Contamination/Cleaning, Harm/Checking, Symmetry/Ordering, and Hoarding are the most replicated dimensions, although others (Sexual/Religious obsessions and Somatic obsessions) have been proposed (Bloch et al., 2008; Mataix-Cols et al., 2005). The finding that these OC symptom dimensions are similar across the lifespan (Mataix-Cols et al., 2008; Stewart et al., 2008), temporally stable in longitudinal studies (MataixCols et al., 2002; Rufer et al., 2005) and probably universal (Matsunaga et al., 2008) further supports their validity. Preliminary evidence also suggests that these OC symptom dimensions have distinct genetic (Alsobrook et al., 1999; Samuels et al., 2008) and neural correlates (Mataix-Cols and van den Heuvel, 2006; van den Heuvel et al., 2008) and are associated with a differential treatment response (Mataix-Cols et al., 2005).

Information on these symptom dimensions has originated almost exclusively from clinical samples. A few studies have reported the prevalence of individual OC symptoms in the general population (Fullana et al., 2009; Nestadt et al., 1994; Stein et al., 1997) but only one study examined the prevalence of OC symptoms or dimensions in the absence of other mental disorders (Fullana et al., 2009). The latter is important in order to determine the impact of these symptoms on the individual's life, independently from their co-occurring psychiatric disorders.

Little is known also about the sociodemographic correlates of these dimensions in the general population. In clinical samples, for example, Contamination/Cleaning symptoms are more prevalent in females and Symmetry/Ordering symptoms in males (Labad et al., 2008) but it is unknown whether this is also true in the general population. One epidemiological study showed that Hoarding is associated with male sex, older age and low income (Samuels et al., 2008), but no data is available for the other dimensions.

Finally, in clinical samples the presence of certain symptom dimensions is associated with an increased risk for specific mental disorders. For example, patients with Harm/Checking symptoms have increased risk for anxiety and mood disorders (Hasler et al., 2005). In contrast, in the general population, the association between particular symptom types and psychiatric disorders appears to be less specific (Fullana et al., 2009) but more data is required to replicate and extend these findings.

In this study we analyzed data from the European Study of the Epidemiology of Mental Disorders (ESEMeD) project in order to clarify some of the above issues regarding OC symptom dimensions in the community. Our research questions were: what is the life time prevalence of OC symptom dimensions in the European population?; are these symptom dimensions associated with particular sociodemographic variables?; and are they associated with the presence of certain psychiatric conditions?

\section{Method}

\subsection{Sample}

The European Study of the Epidemiology of Mental Disorders (ESEMeD) project is a cross-sectional household survey representative of the non-institutionalised adults (ages 18 or older) of Belgium, France, Germany, Italy, The Netherlands, and Spain. A stratified, multistage, clustered area, probability sample without replacement design was used. Data for the project were provided by 21,425 respondents. Overall weighted response rate was $61.2 \%$, rates ranging from $45.9 \%$ in France to $78.6 \%$ in Spain. A full description of the ESEMeD study methodology can be found elsewhere (Alonso et al., 2004).

The survey was administered in two parts. Part I was administered to all respondents and included diagnostic evaluation of most common mood and anxiety disorders as well as detailed questions about their use of health services, health status and main demographic characteristics. Part II was administered to individuals found to have specific mood and anxiety symptoms in part I ('high risk' individuals) plus a $25 \%$ random subsample of all the other respondents (without these symptoms). Part II included questions about additional disorders, risk factors and other correlates. The total number of respondents who completed part II was 8796. Part II individuals were weighted by the inverse of their probability of selection in order to adjust for differential sampling. This procedure ensures that the weighted part II sample is representative of the whole sample and provides unbiased estimates (Alonzo et al., 2003). More details about sampling and weighting procedures are discussed elsewhere (Heeringa et al., 2008). The questions regarding OC symptom dimensions were asked to a random $33 \%$ of part II individuals. In this article we present data from these respondents $(n=2804)$.

\subsection{Assessment of obsessive-compulsive symptom dimensions}

The initial questions of the OCD section of the CIDI 3.0 (see below) were used to assess OC symptom dimensions. 
Participants were asked if they had ever had "a period in your life lasting two weeks or longer when most days you experienced any of the following unpleasant thoughts, images, or impulses, or repeated behaviors that you felt compelled to do". The answers to the specific questions listed in Table 1 assessed the major symptom dimensions of OCD: Contamination/ Cleaning; Harm/Checking; Symmetry/Ordering; Sexual/ religious; Hoarding; Moral issues; and Somatic obsessions. Each of the endorsed symptom dimensions were coded $1=$ present or $0=$ absent.

\subsection{Assessment of mental and physical disorders}

Mental health status was assessed with the Composite International Diagnostic Interview (CIDI) 3.0, which was developed and adapted by the Coordinating Committee of the WHO World Mental Health (WMH) Survey Initiative (Kessler and Ustun, 2004). The validity of the CIDI has been reported previously (Haro et al., 2006). Lifetime diagnoses included in this paper were DSM-IV major depressive episode, dysthymia, alcohol-related disorders and anxiety disorders (specific phobia, agoraphobia, social phobia, generalized anxiety disorder, panic disorder, and post-traumatic stress disorder). The following lifetime groups were also generated: "pure" anxiety disorder and "pure" mood disorder (participants fulfilling criteria for any anxiety or any mood disorder respectively that did not fulfill criteria for other mental disorders), and any mental disorder (participants fulfilling criteria for any lifetime mental disorder). Unfortunately, we were not able to ascertain how many individuals fulfilled the criteria for OCD in this sample because a skip logic error was detected which terminated the OCD assessment prematurely for some respondents before OCD had been ruled out. Anyway, in this study we were not interested in OCD diagnosis but in OC symptom dimensions.

Also included in the CIDI was a list of chronic physical health conditions, which was used to generate the category "any chronic physical condition" (present/absent) in order to establish the specificity of the association between OC symptom dimensions and mental disorders, independently from overall illness status.

\subsection{Statistical analysis}

The percentage of individuals endorsing each OC symptom dimension across age, gender, income, geographical area, anxiety disorders, mood disorders and chronic physical conditions was calculated. Logistic regression models adjusted for age, gender, income and country were generated for each OC symptom dimension as a dependent variable. Independent variables included were those that were significant in bivariate analyses. ORs adjusting for age, gender, income, country and specific mental disorders were obtained to assess the association between each symptom dimension and the presence of the most common axis I disorders. Standard errors were estimated using the Taylor series linearization method (LaVange et al., 1996) implemented in SUDAAN V9.0.1, a statistical package used to analyse data obtained from complex design surveys (i.e. multistage, stratified, unequally weighted or clustered) (Research Triangle Institute, 2004) Significance tests were performed with Wald $\chi^{2}$ tests, using Taylor series design-based coefficient variance-covariance matrices. Significance tests were all evaluated at the 0.05 level with two-sided tests, except for between-group comparisons, where the Bonferroni correction for multiple comparisons was used ( $\propto=0.005$ ).

Effect coding was used to test any possible country effects. This form of contrasting allows to test the deviation of each country from an "average European" effect, the so called grand mean (Hosmer and Lemeshow, 1989). In order to obtain identification the effect for an arbitrary reference category is estimated as the negative sum of all the other effects, so that all effects sum up to zero. This negative sum and the respective standard error can easily be computed and none of the six country effects must be omitted during the presentation of the computed logistic regression models, as dummy coding would stipulate (Aiken and West, 1991).

Data were weighted to account for known probabilities of selection as well as to restore age and gender distribution of the population within countries and the relative dimension of the population across countries.

\section{Results}

\subsection{Lifetime prevalence of obsessive-compulsive symptom dimensions}

The overall lifetime prevalence of any obsessive-compulsive symptom dimension was $13 \%$. For the whole sample, Harm/ Checking (7.8\%) was the most prevalent dimension, followed by Somatic obsessions (4.6\%) and Symmetry/Ordering (3.1\%). The prevalence of Hoarding was $2.6 \%$ and that of Contamination/ Cleaning was $1.8 \%$ (Table 2 ).

Table 1

Specific questions for the assessment of obsessive-compulsive symptom dimensions in the ESEMeD study.

\begin{tabular}{|c|c|}
\hline Lead in statement & $\begin{array}{l}\text { Have you ever had a period in your life lasting } 2 \text { weeks or longer when most days you experienced any of the following } \\
\text { unpleasant thoughts, images, or impulses, or repeated behaviors that you felt compelled to do? }\end{array}$ \\
\hline OC symptom dimension & Question \\
\hline Contamination/Cleaning & A recurrent concern about dirt, germs, contamination, or feeling compelled to repeatedly wash, clean, or decontaminate things \\
\hline Harm/Checking & $\begin{array}{l}\text { A recurrent impulse either to check things like locks or stoves, or to go back over things in your mind to make sure that a } \\
\text { mistake was not made or impulses to do terrible things to people or recurrent concerns that you might do something terrible }\end{array}$ \\
\hline Symmetry/Ordering & $\begin{array}{l}\text { A recurrent impulse either to line things up, to order or arrange things, to touch things, to count things, or to do things in } \\
\text { an exactly defined order }\end{array}$ \\
\hline Sexual/Religious obsessions & Recurrent sexual or religious thoughts, images, or impulses that you found unpleasant, intrusive, and disturbing \\
\hline Hoarding & A compulsion to save things or hoard things \\
\hline Moral issues & Recurrent unpleasant thoughts about right and wrong, or a compulsion to pray over and over to ask forgiveness \\
\hline Somatic obsessions & A recurrent concern that you or someone close to you had a terrible illness that hadn't yet caused any symptoms \\
\hline
\end{tabular}


Table 2

Description of the study sample and prevalence of obsessive-compulsive symptom dimensions according to different groups.

\begin{tabular}{|c|c|c|c|c|c|c|c|c|c|c|}
\hline \multicolumn{3}{|c|}{ Sample characteristics } & \multicolumn{8}{|c|}{ Prevalence of obsessive-compulsive symptom dimensions } \\
\hline & \multirow[b]{2}{*}{$n$} & \multirow[b]{2}{*}{$\%(\mathrm{SE})$} & \multirow{2}{*}{$\begin{array}{l}\text { Any } \\
\text { symptom } \\
\text { dimension } \\
(n=456) \\
\%(S E)\end{array}$} & \multirow{2}{*}{$\begin{array}{l}\text { Contamination/ } \\
\text { Cleaning } \\
(n=73) \\
\%(S E)\end{array}$} & \multirow{2}{*}{$\begin{array}{l}\text { Harm/ } \\
\text { Checking } \\
(n=271) \\
\%(S E)\end{array}$} & \multirow{2}{*}{$\begin{array}{l}\text { Symmetry/ } \\
\text { Ordering } \\
(n=122) \\
\%(S E)\end{array}$} & \multirow{2}{*}{$\begin{array}{l}\text { Hoarding } \\
(n=98) \\
\%(S E)\end{array}$} & \multirow{2}{*}{$\begin{array}{l}\text { Sexual/ } \\
\text { Religious } \\
(n=36) \\
\%(S E)\end{array}$} & \multirow{2}{*}{$\begin{array}{l}\text { Moral } \\
\text { issues } \\
(n=64) \\
\%(S E)\end{array}$} & \multirow{2}{*}{$\begin{array}{l}\text { Somatic } \\
\text { obsessions } \\
(n=146)\end{array}$} \\
\hline & & & & & & & & & & \\
\hline Whole sample & 2804 & - & $13(0.92)$ & $1.8(0.32)$ & $7.8(0.76)$ & $3.1(0.46)$ & $2.6(0.40)$ & $0.7(0.19)$ & $1.4(0.27)$ & $4.6(0.54)$ \\
\hline \multicolumn{11}{|l|}{ Age categories } \\
\hline $18-24$ & 211 & $11.5(1.08)$ & $11.8(2.77)$ & $3(1.40)$ & $7.2(2.30)$ & $2.2(1.23)$ & $1.6(1.29)$ & $0.9(0.78)$ & $1.7(0.94)$ & $5(1.70)$ \\
\hline $25-49$ & 1316 & $44.8(1.50)$ & $13.7(1.40)$ & $1.6(0.42)$ & $8.8(1.22)$ & $3.7(0.77)$ & $2.9(0.64)$ & $0.9(0.34)$ & $1.8(0.51)$ & $4.6(0.79)$ \\
\hline $50+$ & 1277 & $43.7(1.50)$ & $12.7(1.32)$ & $1.7(0.48)$ & 7 (0.99) & $2.7(0.63)$ & $2.5(0.55)$ & $0.5(0.19)$ & $0.9(0.24)$ & $4.5(0.80)$ \\
\hline$p$-value & - & - & 0.8 & 0.626 & 0.489 & 0.482 & 0.669 & 0.601 & 0.233 & 0.971 \\
\hline \multicolumn{11}{|l|}{ Gender } \\
\hline Male & 1152 & $47.9(1.48)$ & $9.1(1.05)$ & $0.7(0.29)$ & $5.6(0.82)$ & $2(0.55)$ & $2.2(0.55)$ & $0.9(0.35)$ & $1.4(0.45)$ & $2.5(0.63)$ \\
\hline Female & 1652 & $52.1(1.48)$ & $16.6(1.41)$ & $2.9(0.56)$ & $9.9(1.20)$ & $4(0.73)$ & $2.9(0.58)$ & $0.6(0.18)$ & $1.4(0.30)$ & $6.5(0.86)$ \\
\hline$p$-value & - & - & $<\mathbf{0 . 0 0 1}$ & $<0.001$ & 0.003 & 0.022 & 0.344 & 0.437 & 0.917 & $<0.001$ \\
\hline \multicolumn{11}{|l|}{ Income $^{\mathrm{a}}$} \\
\hline Low & 509 & 19.5 (1.15) & $19(2.50)$ & $2.5(0.68)$ & $12.2(2.09)$ & $5.7(1.44)$ & $5.7(1.52)$ & $0.6(0.23)$ & $2.8(1.01)$ & $8.2(1.85)$ \\
\hline Low average & 881 & $31.4(1.38)$ & $11.1(1.52)$ & $1.8(0.64)$ & $7.6(1.39)$ & $1.9(0.62)$ & $1.8(0.47)$ & $0.8(0.35)$ & $0.4(0.17)$ & $3(0.64)$ \\
\hline High average & 926 & $32.3(1.41)$ & $11.9(1.54)$ & $1.5(0.59)$ & $6(1.17)$ & $3.4(0.91)$ & $1.9(0.54)$ & $1.1(0.47)$ & $1.9(0.50)$ & $4(0.89)$ \\
\hline High & 488 & $16.8(1.11)$ & $11.7(1.93)$ & $1.6(0.66)$ & $6.8(1.47)$ & $1.6(0.53)$ & $1.7(0.76)$ & $0.2(0.13)$ & $0.4(0.20)$ & 3.7 (1.07) \\
\hline$p$-value & - & - & 0.046 & 0.707 & 0.084 & 0.030 & 0.099 & 0.091 & 0.001 & 0.062 \\
\hline \multicolumn{11}{|l|}{ Geographical } \\
\hline Rural & 759 & $31.2(1.43)$ & $15.6(1.80)$ & $2(0.59)$ & $9.1(1.43)$ & $3.1(0.72)$ & $3.2(0.78)$ & $1.4(0.53)$ & $1.4(0.53)$ & $6(1.04)$ \\
\hline Midsize & 1275 & $40.4(1.45)$ & $11.5(1.32)$ & $2.1(0.61)$ & 6.7 (1.07) & $2.7(0.66)$ & $2.5(0.65)$ & $0.5(0.23)$ & $1.5(0.48)$ & $3.8(0.79)$ \\
\hline Large & 770 & $28.4(1.39)$ & $12.3(1.74)$ & $1.1(0.34)$ & $8(1.51)$ & $3.6(1.06)$ & $2(0.63)$ & $0.4(0.15)$ & $1.2(0.34)$ & $4.2(0.99)$ \\
\hline$p$-value & - & - & 0.169 & 0.210 & 0.386 & 0.772 & 0.520 & 0.183 & 0.827 & 0.205 \\
\hline \multicolumn{11}{|c|}{ Any anxiety disorder } \\
\hline Yes & 594 & $14.1(0.93)$ & $26.3(2.85)$ & $4.7(1.12)$ & $17.3(2.52)$ & $6.3(1.47)$ & $5.6(1.31)$ & $2.3(0.67)$ & $2.7(0.67)$ & $11.7(2.01)$ \\
\hline No & 2210 & $85.9(0.93)$ & $10.8(0.93)$ & $1.3(0.33)$ & $6.3(0.76)$ & $2.55(0.48)$ & $2.1(0.41)$ & $0.5(0.20)$ & $1.2(0.30)$ & $3.4(0.52)$ \\
\hline$p$-value & - & - & $<0.001$ & 0.003 & $<0.001$ & 0.015 & 0.010 & 0.008 & 0.036 & $<0.001$ \\
\hline \multicolumn{11}{|c|}{ Any mood disorder } \\
\hline Yes & 979 & $13.5(0.66)$ & $26.8(2.02)$ & $6.1(1.06)$ & $16.7(1.78)$ & $7.2(1.30)$ & $4.4(0.80)$ & $2(0.57)$ & $3.9(0.77)$ & $10.7(1.47)$ \\
\hline No & 1825 & $86.5(0.66)$ & $10.9(1.01)$ & $1.2(0.33)$ & $6.5(0.83)$ & $2.4(0.49)$ & $2.3(0.44)$ & $0.6(0.20)$ & $1(0.29)$ & $3.6(0.57)$ \\
\hline$p$-value & - & - & $<\mathbf{0 . 0 0 1}$ & $<0.001$ & $<\mathbf{0 . 0 0 1}$ & $<\mathbf{0 . 0 0 1}$ & 0.020 & 0.020 & $<\mathbf{0 . 0 0 1}$ & $<\mathbf{0 . 0 0 1}$ \\
\hline \multicolumn{11}{|c|}{ Any pure anxiety disorder } \\
\hline Yes & 228 & $8.3(0.82)$ & $23(4.14)$ & $2.7(1.23)$ & $16.2(3.71)$ & 4.7 (1.97) & $3.9(1.81)$ & $0.6(0.37)$ & $1.7(0.73)$ & $10.8(3.04)$ \\
\hline No & 2576 & $91.7(0.82)$ & $12.1(0.90)$ & $1.7(0.34)$ & $7(0.74)$ & $2.9(0.47)$ & $2.5(0.40)$ & $0.8(0.21)$ & $1.4(0.29)$ & $4(0.50)$ \\
\hline$p$-value & - & - & 0.010 & 0.475 & 0.017 & 0.388 & 0.449 & 0.802 & 0.702 & 0.027 \\
\hline \multicolumn{11}{|c|}{ Any pure mood disorder } \\
\hline Yes & 979 & $13.5(0.66)$ & $24(2.56)$ & $5.6(1.35)$ & $15.2(2.30)$ & $6.6(1.64)$ & $2.4(0.69)$ & $0.7(0.33)$ & $3.4(0.89)$ & $9(1.93)$ \\
\hline No & 1825 & $86.5(0.66)$ & $12(0.97)$ & $1.5(0.33)$ & $7.2(0.79)$ & $2.8(0.48)$ & $2.6(0.43)$ & $0.8(0.21)$ & $1.2(0.29)$ & $4(0.55)$ \\
\hline$p$-value & - & - & $<0.001$ & 0.003 & 0.001 & 0.029 & 0.831 & 0.873 & 0.021 & 0.017 \\
\hline Any mental diso & & & & & & & & & & \\
\hline Yes & 1519 & $74.1(1.16)$ & $22.7(1.86)$ & $4.4(0.76)$ & 14.5 (1.59) & $5.5(0.96)$ & $4.3(0.87)$ & $1.5(0.38)$ & $2.7(0.49)$ & $9.3(1.28)$ \\
\hline No & 1285 & $25.9(1.16)$ & $9.6(1.03)$ & $0.9(0.35)$ & $5.5(0.84)$ & $2.2(0.53)$ & $2(0.44)$ & $0.5(0.23)$ & $0.9(0.33)$ & $3(0.56)$ \\
\hline$p$-value & - & - & $<0.001$ & $<0.001$ & $<0.001$ & 0.002 & 0.019 & 0.022 & 0.002 & $<0.001$ \\
\hline Any chronic phy & ical con & ition & & & & & & & & \\
\hline Yes & 2039 & $70.5(1.42)$ & $14.5(1.14)$ & 1.9 (0.39) & $9(0.95)$ & $2.9(0.49)$ & $2.9(0.51)$ & $0.6(0.20)$ & $1.3(0.31)$ & $5.1(0.69)$ \\
\hline No & 765 & $29.5(1.42)$ & $9.4(1.43)$ & $1.6(0.58)$ & $5.1(1.11)$ & $3.5(1.04)$ & $1.8(0.60)$ & $1(0.45)$ & $1.5(0.52)$ & $3.2(0.73)$ \\
\hline$p$-value & - & - & 0.004 & 0.663 & 0.007 & 0.617 & 0.177 & 0.481 & 0.794 & 0.050 \\
\hline
\end{tabular}

Unadjusted results.

Significant differences between-groups at $\mu=0.005$ (Bonferroni correction) are highlighted in bold.

${ }^{a}$ With respect to median income in each country. 
Among individuals with no mental disorders ( $n=1,285)$, the lifetime prevalence of any obsessive-compulsive symptom was 9.6\%. In this group, the prevalence of Contamination/ Cleaning, Harm/Checking, Symmetry/Ordering, Hoarding, Sexual/religious, Moral issues and Somatic obsessions were respectively: $0.9 \%, 5.5 \%, 2.2 \%, 2 \%, 0.5 \%, 0.9 \%$ and $3 \%$ (Table 2 ).

\subsection{Association with sociodemographic variables (univariate analyses)}

As seen in Table 2, the prevalence of symptom dimensions was similar across age groups but women had a significantly higher lifetime prevalence of Contamination/Cleaning, Harm/ Checking, and Somatic obsessions. The prevalence of most symptom dimensions tended to be higher among low income participants, although this difference only reached statistical significance for Moral issues. There were no significant differences in prevalence according to geographical areas (i.e. rural, midsize towns or large cities).

\subsection{Association with psychiatric and physical conditions (univariate analyses)}

The prevalence of most lifetime obsessive-compulsive symptom dimensions was more than double in participants with lifetime mental disorders, particularly mood disorders (Table 2). Interestingly, the presence of any chronic physical condition also increased the prevalence of obsessive-compulsive symptoms albeit to a smaller degree ( $14.5 \%$ vs. $9.4 \% ; p=0.004)$.

\subsection{Multivariate analyses}

Table 3 shows the factors associated with each OC symptom dimension in the European population. Females were more likely to have lifetime symptoms in two dimensions: Contamination/Cleaning $(\mathrm{OR}=3,95 \% \mathrm{CI}=1.06-8.51)$ and Somatic obsessions ( $\mathrm{OR}=1.88,95 \% \mathrm{CI}=1.05-3.37)$. Individuals with low income had higher odds of presenting any of the symptom dimensions except Contamination/ Cleaning, Harm/Checking and Sexual/Religious obsessions as compared to those with high income. Moreover, there was a significant association between high average income and the Moral issues dimension ( $\mathrm{OR} 4.54,95 \% \mathrm{CI}=1.58-13.1$ ).

Pure mood disorders increased the probability of Harm/ Checking (OR 2.93, 95\%CI = 1.56-5.52) and Somatic obsessions (OR 3.46, 95\%CI =1.63-7.32), whereas pure anxiety disorders increased the probability of all symptom dimensions except Hoarding and Sexual/Religious obsessions. Comorbidity of anxiety and mood disorders increased the probability of all symptom dimensions. There was no significant association between any of the symptom dimensions and chronic physical disorders.

Multivariate analyses also showed that respondents in France (OR 1.98, 95\% CI =1.35-2.91) and Italy (OR 1.35, 95\% $\mathrm{CI}=1.01-1.79$ ) had an increased risk and The Netherlands (OR $0.45,95 \% \mathrm{CI}=0.29-0.68$ ) a decreased risk of "any symptom dimension" when compared to the average of the six European countries as the reference category. Differences also emerged regarding specific dimensions, and for example, respondents in France had an increased risk of Harm/Checking and respondents in Italy an increased risk of Somatic obsessions (see Table 3).

\subsection{Association with specific mental disorders}

The presence of all symptom dimensions was significantly associated with increased risk of most axis I disorders except alcohol disorder, and, surprisingly, generalized anxiety disorder (Table 4). Harm/Checking was the dimension that increased the risk of most disorders. Hoarding symptoms were significantly associated with increased risk of dysthymia (OR 2.14, 95\%CI = 1.04-4.40), post-traumatic stress disorder (OR 2.44, 95\%CI = 1.01-5.92), and specific phobia (OR 2.97, $95 \% \mathrm{CI}=1.27-6.94)$. There were no specific dimension-disorder relationships.

\section{Discussion}

This is one of the very few reports of the lifetime prevalence and correlates of specific OC symptom dimensions in a large epidemiological sample. Four conclusions can be drawn from the data.

First, OC symptom dimensions are highly prevalent in the community. We found an overall lifetime prevalence of $13 \%$ for any of the symptom dimensions, which is at least five times higher than that of people meeting strict diagnostic criteria for OCD (Ruscio et al., 2008). This prevalence is somewhat lower than that reported in some other epidemiological studies (Fullana et al., 2009; Ruscio et al., 2008; Stein et al., 1997). However the current and previous studies differ in a number of important ways that make it difficult to directly compare their findings. Indeed, different studies employed different instruments, assessed different number and types of OC symptoms and used different time frames (e.g. lifetime vs. 1-year prevalence). In our study we used a relatively stringent criterion whereby, to endorse a symptom, the individual must have a period of his or her life lasting 2 weeks or longer when most days they experienced any obsessions and/or compulsions. This may have resulted in more conservative prevalence estimates. However, methodological differences do not appear to fully explain the differences between the results of the current study and those of the NCS-R (Ruscio et al., 2008), which used very similar methods and instruments but reported a much higher prevalence of "any obsession or compulsion" $(28 \%)^{2}$. It is therefore possible that other variables, such as cultural differences, may contribute to different prevalence of OC symptom dimensions in different parts of the world, just as they influence the prevalence of most mental disorders (Demyttenaere et al., 2004). In support for this idea, we also found some slight differences between European countries, despite the use of identical instruments and methods. It is of course not possible to fully rule out the effect of methodological confounds, such the adaptation of the instruments to different languages. Careful, indepth trans-cultural studies of OC symptoms are still lacking.

We were also able to estimate the lifetime prevalence of OC symptom dimensions in individuals not meeting criteria for any

\footnotetext{
2 The wording of the questions related to OC symptoms in the NCS-R and ESEMeD studies were identical except for hoarding. Participants in the NCS-R were asked about "a compulsion to save things or being unable to throw things away that you no longer need", i.e., both hoarding obsessions and compulsions were assessed. In the ESEMeD study only hoarding compulsions were assessed ("a compulsion to save things or hoard things").
} 
Table 3

Effect of sociodemographic variables, mental and physical disorders and country on obsessive-compulsive symptom dimensions (multivariate model).

\begin{tabular}{|c|c|c|c|c|c|c|c|c|c|c|c|c|c|c|c|c|}
\hline & \multicolumn{2}{|c|}{$\begin{array}{l}\text { Any symptom } \\
\text { dimension } \\
(n=456)\end{array}$} & \multicolumn{2}{|c|}{$\begin{array}{l}\text { Contamination/ } \\
\text { Cleaning } \\
(n=73) \\
\end{array}$} & \multicolumn{2}{|c|}{$\begin{array}{l}\text { Harm/Checking } \\
(n=271)\end{array}$} & \multicolumn{2}{|c|}{$\begin{array}{l}\text { Symmetry/Ordering } \\
(n=122)\end{array}$} & \multicolumn{2}{|c|}{$\begin{array}{l}\text { Hoarding } \\
(n=95)\end{array}$} & \multicolumn{2}{|c|}{$\begin{array}{l}\text { Sexual/Religious } \\
(n=36)\end{array}$} & \multicolumn{2}{|c|}{$\begin{array}{l}\text { Moral issues } \\
(n=64)\end{array}$} & \multicolumn{2}{|c|}{$\begin{array}{l}\text { Somatic obsessions } \\
(n=146)\end{array}$} \\
\hline & $\begin{array}{l}\text { Odds } \\
\text { ratio }\end{array}$ & $95 \%$ CI & $\begin{array}{l}\text { Odds } \\
\text { ratio }\end{array}$ & $95 \% \mathrm{CI}$ & $\begin{array}{l}\text { Odds } \\
\text { ratio }\end{array}$ & $95 \% \mathrm{CI}$ & $\begin{array}{l}\text { Odds } \\
\text { ratio }\end{array}$ & $95 \% \mathrm{CI}$ & $\begin{array}{l}\text { Odds } \\
\text { ratio }\end{array}$ & $95 \% \mathrm{CI}$ & $\begin{array}{l}\text { Odds } \\
\text { ratio }\end{array}$ & $95 \% \mathrm{CI}$ & $\begin{array}{l}\text { Odds } \\
\text { ratio }\end{array}$ & $95 \% \mathrm{CI}$ & $\begin{array}{l}\text { Odds } \\
\text { ratio }\end{array}$ & $95 \% \mathrm{CI}$ \\
\hline \multicolumn{17}{|l|}{ Age (Ref: $50+$ ) } \\
\hline $18-24$ & 0.93 & $(0.51,1.69)$ & 1.81 & $(0.59,5.57)$ & 0.96 & $(0.45,2.04)$ & 0.61 & $(0.17,2.17)$ & 0.64 & $(0.11,3.60)$ & 1.45 & $(0.23,9.25)$ & 1.74 & $(0.52,5.82)$ & 1.05 & $(0.46,2.41)$ \\
\hline $25-49$ & 1.17 & $(0.84,1.65)$ & 0.85 & $(0.35,2.08)$ & 1.32 & $(0.86,2.04)$ & 1.33 & $(0.71,2.47)$ & 1.45 & $(0.73,2.85)$ & 1.41 & $(0.48,4.18)$ & 1.93 & $(0.82,4.57)$ & 1.12 & $(0.67,1.89)$ \\
\hline Sex (Ref: male) & 1.57 & $(1.12,2.20)$ & 3 & $(1.06,8.51)$ & 1.37 & $(0.89,2.12)$ & 1.79 & $(0.85,3.77)$ & 1.34 & $(0.65,2.76)$ & 0.54 & $(0.22,1.33)$ & 0.84 & $(0.37,1.90)$ & 1.88 & $(1.05,3.37)$ \\
\hline \multicolumn{17}{|l|}{ Income (Ref: high) } \\
\hline Low & 1.65 & $(0.97,2.81)$ & 1.77 & $(0.68,4.59)$ & 1.92 & $(1.03,3.60)$ & 3.87 & $(1.54,9.74)$ & 2.97 & $(0.97,9.08)$ & 2.47 & $(0.53,11.5)$ & 5.82 & $(1.65,20.6)$ & 2.05 & $(0.91,4.62)$ \\
\hline Low average & 0.93 & $(0.56,1.54)$ & 1.62 & $(0.52,5.00)$ & 1.19 & $(0.64,2.21)$ & 1.19 & $(0.45,3.16)$ & 0.99 & $(0.33,3.02)$ & 3.62 & $(0.69,19.1)$ & 1.03 & $(0.31,3.42)$ & 0.72 & $(0.34,1.54)$ \\
\hline High average & 1.03 & $(0.63,1.69)$ & 1.39 & $(0.47,4.14)$ & 0.94 & $(0.49,1.77)$ & 2.15 & $(0.85,5.46)$ & 1 & $(0.33,3.00)$ & 4.63 & $(0.99,21.5)$ & 4.54 & $(1.58,13.1)$ & 1.09 & $(0.52,2.25)$ \\
\hline \multicolumn{17}{|l|}{ Anxiety/Mood (Ref: no) } \\
\hline Pure mood & 2.49 & $(1.50,4.14)$ & 2.58 & $(0.76,8.76)$ & 2.93 & $(1.56,5.52)$ & 2.11 & $(0.75,5.98)$ & 1.93 & $(0.61,6.06)$ & 1.57 & $(0.39,6.36)$ & 1.78 & $(0.54,5.89)$ & 3.46 & $(1.63,7.32)$ \\
\hline Pure anxiety & 2.34 & $(1.57,3.48)$ & 5.27 & $(1.88,14.8)$ & 2.28 & $(1.35,3.86)$ & 2.43 & $(1.14,5.17)$ & 0.92 & $(0.38,2.18)$ & 1.54 & $(0.42,5.65)$ & 4.06 & $(1.64,10.0)$ & 2.91 & $(1.57,5.38)$ \\
\hline Comorbidity anxiety/Mood & 3.32 & $(2.13,5.16)$ & 6.75 & $(2.25,20.3)$ & 2.8 & $(1.58,4.94)$ & 3.13 & $(1.34,7.33)$ & 3.17 & $(1.45,6.93)$ & 8.5 & $(2.74,26.4)$ & 4.99 & $(1.87,13.3)$ & 4.63 & $(2.50,8.58)$ \\
\hline \multicolumn{17}{|l|}{ Any chronic } \\
\hline Physical condition (Ref: no) & 1.4 & $(0.94,2.07)$ & 0.75 & $(0.32,1.76)$ & 1.55 & $(0.92,2.63)$ & 0.67 & $(0.34,1.35)$ & 1.38 & $(0.60,3.18)$ & 0.54 & $(0.15,1.94)$ & 0.87 & $(0.33,2.24)$ & 1.38 & $(0.76,2.48)$ \\
\hline \multicolumn{17}{|l|}{ Country* } \\
\hline Belgium & 0.95 & $(0.65,1.39)$ & 0.86 & $(0.42,1.79)$ & 1 & $(0.61,1.64)$ & 1.51 & $(0.87,2.63)$ & 1.85 & $(1.00,3.44)$ & 1.33 & $(0.47,3.73)$ & 0.71 & $(0.30,1.72)$ & 0.43 & $(0.17,1.11)$ \\
\hline France & 1.98 & $(1.35,2.91)$ & 1.65 & $(0.62,4.37)$ & 2.64 & $(1.68,4.16)$ & 1.99 & $(0.94,4.22)$ & 1.94 & $(1.01,3.74)$ & 3.9 & $(1.45,10.5)$ & 1.25 & $(0.47,3.32)$ & 1.23 & $(0.67,2.28)$ \\
\hline Germany & 0.91 & $(0.65,1.27)$ & 0.66 & $(0.33,1.34)$ & 0.9 & $(0.58,1.39)$ & 0.51 & $(0.23,1.11)$ & 0.41 & $(0.16,1.05)$ & 0.83 & $(0.25,2.72)$ & 0.83 & $(0.28,2.44)$ & 1.4 & $(0.82,2.41)$ \\
\hline Italy & 1.35 & $(1.01,1.79)$ & 1.78 & $(0.99,3.20)$ & 1.34 & $(0.93,1.92)$ & 1.12 & $(0.69,1.80)$ & 1.87 & $(1.08,3.24)$ & 0.44 & $(0.15,1.29)$ & 1.65 & $(0.86,3.18)$ & 2.15 & $(1.40,3.31)$ \\
\hline The Netherlands & 0.45 & $(0.29,0.68)$ & 0.52 & $(0.17,1.55)$ & 0.36 & $(0.20,0.64)$ & 0.39 & $(0.20,0.78)$ & 0.21 & $(0.09,0.49)$ & 0.38 & $(0.10,1.50)$ & 0.73 & $(0.27,1.93)$ & 0.45 & $(0.19,1.10)$ \\
\hline Spain & 0.97 & $(0.70,1.34)$ & 1.15 & $(0.52,2.58)$ & 0.87 & $(0.57,1.32)$ & 1.5 & $(0.82,2.73)$ & 1.71 & $(0.79,3.70)$ & 1.39 & $(0.54,3.59)$ & 1.12 & $(0.60,2.12)$ & 1.37 & $(0.73,2.57)$ \\
\hline
\end{tabular}

Logistic regression models for each OC symptom dimension controlling for age, gender, income and country. * Effect coding was used to test deviation of each country from an "average European".

Significant associations are highlighted in bold. 


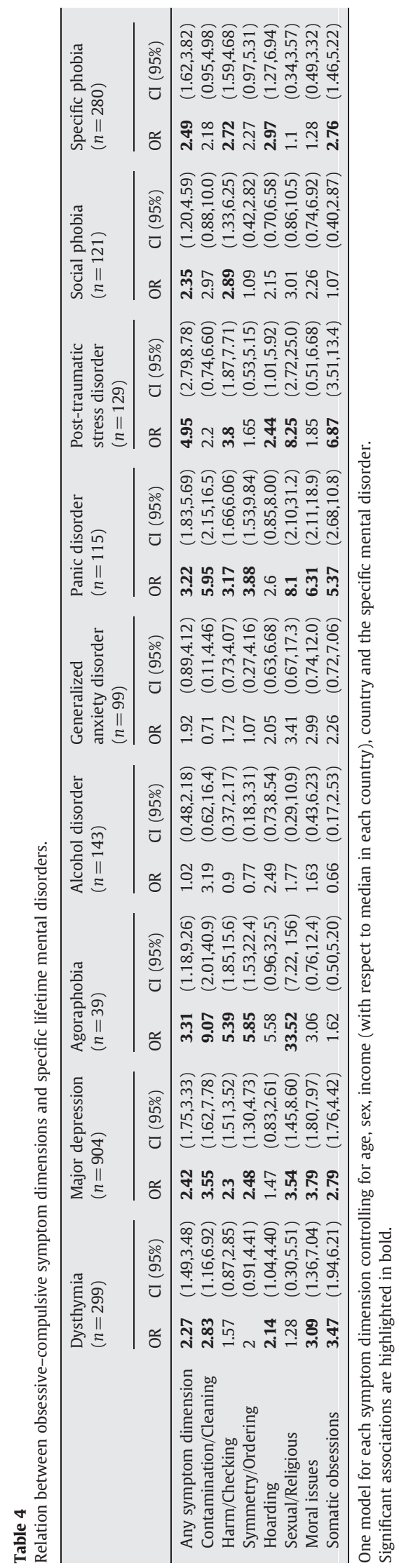

mental disorder, which was in the region of $10 \%$. These findings confirm those of a previous population-based study that reported a 1 -year prevalence of OC symptoms ranging between 13 and 17\% (Fullana et al., 2009) and suggest that a substantial proportion of the general population experience moderately interfering OC symptoms, independently from the presence of other mental disorders. While it is likely that many of these individuals will never go on to develop full-blown OCD or require treatment, there is at least one longitudinal study that found that the presence of OC symptoms in childhood (age 11) was associated with a 5-fold increase risk of full-blown OCD 20 years later (Fullana et al., 2009).

Second, the frequency of specific symptom dimensions in the community does not correspond exactly with that reported in clinical samples. In our sample, Harm/Checking was the most prevalent dimension followed by Somatic obsessions and Symmetry/Ordering. Like in a previous population-based study (Fullana et al., 2009), Contamination/Cleaning symptoms were relatively infrequent (2\%). By contrast, in clinical samples, Contamination/Cleaning tends to be the most frequently endorsed symptoms (Mataix-Cols et al., 2005). The apparent differences in prevalence of these symptoms, in epidemiological vs. clinical samples may simply reflect that Contamination/ Cleaning symptoms are more easily recognized and diagnosed by clinicians than other types of symptoms and therefore appear to be over-represented in clinical samples.

Third, our data on the sociodemographic correlates of OC symptom dimensions may shed light on previous inconsistencies between clinical and epidemiological samples. For example, although most studies in clinical samples show a predominance of females, the results from epidemiological samples are less conclusive (Fontenelle and Hasler, 2008). Our data suggest that the effect of gender on OC dimensions may account for some of these inconsistencies, with females being more likely to present with Contamination/Cleaning symptoms (and may be also more likely to seek treatment and "inflate" clinical samples) as well as Somatic obsessions. An alternative possibility is that in the general population the prevalence of full-blown OCD is higher in women whereas the prevalence of sub-syndromal OCD is similar in both genders (Grabe et al., 2000).

Fourth, all symptom dimensions were associated with an increased risk of most mental disorders and this was independent from the presence of any chronic physical illness. Consistent with previous clinical studies (Hasler et al., 2005) the presence of Harm/Checking symptoms was most strongly associated with a wide range of mental disorders. The specificity of the relationship with particular psychiatric disorders was, however, less clear than in previous clinical studies (Hasler et al., 2005). It is also unclear from the data whether the presence of certain mental disorders increases the likelihood of having certain $\mathrm{OC}$ symptoms or vice versa.

\subsection{Limitations}

Our study has several limitations. First, we have no data on the validity of the CIDI to assess symptom dimensions, although a clinical reappraisal study of the NCS-R revealed good concordance between CIDI and SCID diagnoses of DSM-IV OCD (Ruscio et al., 2008). Furthermore, we were not able to assess some characteristics of obsessions/compulsions such as the ego-dystonic nature of obsessions or the impression that 
compulsions are excessive and absurd. Also, in our study we assessed seven OC dimensions while most clinical studies focus on four to six dimensions. Second, we were also not able to assess separately the interference caused by each dimension and this should be a focus of future research. Furthermore, as occurred with other studies (Ruscio et al., 2008), sample sizes in our analyses were relatively small for epidemiological standards because OCD was assessed only in a subsample of the part II sample. Finally, we were not able to ascertain how many individuals fulfilled criteria for OCD in this sample because of the previously mentioned skip logic error, although this does not affect the estimates for the prevalence of OC dimensions.

\subsection{Implications}

The results of our study have implications at different levels. From a research point of view, they add to a growing body of evidence showing that $\mathrm{OC}$ phenomena are much more prevalent than OCD in the community. An important goal for future research will be to understand why the symptoms develop into full-blown in OCD in some individuals but not in others. Only longitudinal designs will eventually answer this question.

Our results on the high prevalence of OC symptom dimensions, in conjunction with previous data on the interference associated with OC symptoms in the community suggest that clinicians need to be aware of the distress that frequently accompanies sub-syndromal cases of OCD. Furthermore, it encourages the use of prevention strategies that may decrease this distress and/or have an impact on the development of the illness.

Finally, our results suggest that at least some previous inconsistencies in the literature on the epidemiology of OCD can be accounted for the heterogeneity (i.e., predominance of some OC dimensions) of the samples studied and strongly encourage that these dimensions be carefully measured in future surveys.

\section{Role of funding source}

The ESEMeD project (http://www.epremed.org) was funded by the European Commission (Contracts QLG5-1999-01042; SANCO 2004123), the Piedmont Region (Italy), Fondo de Investigación Sanitaria, Instituto de Salud Carlos III, Spain (FIS 00/0028-02), Ministerio de Ciencia y Tecnología, Spain (SAF 2000-158-CE), Departament de Salut, Generalitat de Catalunya, Spain, and other local agencies and by an unrestricted educational grant from GlaxoSmithKline.

\section{Conflict of interest}

No conflict declared.

\section{Acknowledgements}

ESEMeD is carried out in conjunction with the World Health Organization World Mental Health (WMH) Survey Initiative. We thank the WMH staff for assistance with instrumentation, fieldwork, and data analysis. We also thank very much Ms. Carme Gasull for editorial assistance.

\section{References}

Aiken, L.S., West, S.G., 1991. Multiple Regression: Testing and interpreting interactions. Sage, Newbury Park, CA.

Alonso, J., Angermeyer, M.C., Bernert, S., Bruffaerts, R., Brugha, T.S., Bryson, H., de Girolamo, G., Graaf, R., Demyttenaere, K., Gasquet, I., Haro, J.M., Katz, S.J.,
Kessler, R.C., Kovess, V., Lepine, J.P., Ormel, J., Polidori, G., Russo, L.J., Vilagut, G., Almansa, J., Arbabzadeh-Bouchez, S., Autonell, J., Bernal, M., BuistBouwman, M.A., Codony, M., Domingo-Salvany, A., Ferrer, M., Joo, S.S., Martinez-Alonso, M., Matschinger, H., Mazzi, F., Morgan, Z., Morosini, P., Palacin, C., Romera, B., Taub, N., Vollebergh, W.A., 2004. Sampling and methods of the European Study of the Epidemiology of Mental Disorders (ESEMeD) project. Acta Psychiatr. Scand. Suppl. 420, 8-20.

Alonzo, T.A., Pepe, M.S., Lumley, T., 2003. Estimating disease prevalence in two-phase studies. Biostatistics 4, 313-326.

Alsobrook, I.J., Leckman, J.F., Goodman, W.K., Rasmussen, S.A., Pauls, D.L., 1999. Segregation analysis of obsessive-compulsive disorder using symptombased factor scores. Am. J. Med. Genet. 88, 669-675.

American Psychiatric Association, 1994. Diagnostic and Statistical Manual of Mental Disorders. American Psychiatric Association, Washington, D.C.

Bloch, M.H., Landeros-Weisenberger, A., Rosario, M.C., Pittenger, C., Leckman, J.F., 2008. Meta-analysis of the symptom structure of obsessivecompulsive disorder. Am. J. Psychiatry 165, 1532-1542.

Demyttenaere, K., Bruffaerts, R., Posada-Villa, J., Gasquet, I., Kovess, V., Lepine, J.P., Angermeyer, M.C., Bernert, S., de Girolamo, G., Morosini, P., Polidori, G., Kikkawa, T., Kawakami, N., Ono, Y., Takeshima, T., Uda, H., Karam, E.G., Fayyad, J.A., Karam, A.N., Mneimneh, Z.N., Medina-Mora, M.E., Borges, G., Lara, C., de Graaf, R., Ormel, J., Gureje, O., Shen, Y., Huang, Y., Zhang, M., Alonso, J., Haro, J.M., Vilagut, G., Bromet, E.J., Gluzman, S., Webb, C., Kessler, R.C., Merikangas, K.R., Anthony, J.C., Von Korff, M.R., Wang, P.S., Brugha, T.S., Aguilar-Gaxiola, S., Lee, S., Heeringa, S., Pennell, B.E., Zaslavsky, A.M., Ustun, T.B., Chatterji, S., 2004. Prevalence, severity, and unmet need for treatment of mental disorders in the World Health Organization World Mental Health Surveys. JAMA 291, 2581-2590.

Fontenelle, L.F., Hasler, G., 2008. The analytical epidemiology of obsessivecompulsive disorder: risk factors and correlates. Prog. Neuro-psychopharmacol. Biol. Psychiatry 32, 1-15.

Fontenelle, L.F., Mendlowicz, M.V., Versiani, M., 2006. The descriptive epidemiology of obsessive-compulsive disorder. Prog. Neuro-psychopharmacol. Biol. Psychiatry 30, 327-337.

Fullana, M.A., Mataix-Cols, D., Caspi, A., Harrington, H., Grisham, J.R., Moffit, T.E., Poulton, R., 2009. Obsessions and compulsions in the community: prevalence, interference, help-seeking, developmental stability and cooccurring psychiatric conditions. Am. J. Psychiatry 329-336.

Grabe, H.J., Meyer, C., Hapke, U., Rumpf, H.J., Freyberger, H.J., Dilling, H., John, U., 2000. Prevalence, quality of life and psychosocial function in obsessive-compulsive disorder and subclinical obsessive-compulsive disorder in northern Germany. Eur. Arch. Psychiatry Clin. Neurosci. 250, 262-268.

Grabe, H.J., Meyer, C., Hapke, U., Rumpf, H.J., Freyberger, H.J., Dilling, H., John, U., 2001. Comorbidity of obsessive-compulsive disorder and subclinical obsessive-compulsive disorder in northern Germany. Eur. Arch. Psychiatry Clin. Neurosci. 251, 130-136.

Haro, J.M., Arbabzadeh-Bouchez, S., Brugha, T.S., de Girolamo, G., Guyer, M.E., Jin, R., Lepine, J.P., Mazzi, F., Reneses, B., Vilagut, G., Sampson, N.A., Kessler, R.C., 2006. Concordance of the Composite International Diagnostic Interview version 3.0 (CIDI 3.0) with standardized clinical assessments in the WHO World Mental Health surveys. Int. J. Methods Psychiatr. Res. 15, 167-180.

Hasler, G., LaSalle-Ricci, V.H., Ronquillo, J.G., Crawley, S.A., Cochran, L.W., Kazuba, D., Greenberg, B.D., Murphy, D.L., 2005. Obsessive-compulsive disorder symptom dimensions show specific relationships to psychiatric comorbidity. Psychiatry Res. 135, 121-132.

Heeringa, S.G., Wells, J.E., Frost, H., Mneimneh, Z.N., Chiu, G.T., Sampson, N.A., Berglund, P.A., 2008. Sample designs and sampling procedures. In: Kessler, Ronald C., Bedirhan Üstün, T. (Eds.), The WHO World Mental Health Surveys: Global Perspectives on the Epidemiology of Mental Disorders. Cambridge University Press, New York, pp. 14-32.

Hosmer, D., Lemeshow, S., 1989. Applied Logistic Regression. John Wiley \& sons, New York.

Kessler, R.C., Ustun, T.B., 2004. The World Mental Health (WMH) Survey Initiative Version of the World Health Organization (WHO) Composite International Diagnostic Interview (CIDI). Int. J. Methods Psychiatr. Res. 13, 93-121.

Labad, J., Menchon, J.M., Alonso, P., Segalas, C., Jimenez, S., Jaurrieta, N., Leckman, J.F., Vallejo, J., 2008. Gender differences in obsessive-compulsive symptom dimensions. Depress. Anxiety 25, 832-838.

LaVange, L.M., Stearns, S.C., Lafata, J.E., Koch, G.G., Shah, B.V., 1996. Innovative strategies using SUDAAN for analysis of health surveys with complex samples. Stat. Methods Med. Res. 5, 311-329.

Mataix-Cols, D., van den Heuvel, O.A., 2006. Common and distinct neural correlates of obsessive-compulsive and related disorders. Psychiatr. Clin. North Am. 29, 391-410.

Mataix-Cols, D., Rauch, S.L., Baer, L., Eisen, J.L., Shera, D.M., Goodman, W.K., Rasmussen, S.A., Jenike, M.A., 2002. Symptom stability in adult obsessivecompulsive disorder: data from a naturalistic two-year follow-up study. Am. J. Psychiatry 159, 263-268. 
Mataix-Cols, D., Rosario-Campos, M.C., Leckman, J.F., 2005. A multidimensional model of obsessive-compulsive disorder. Am. J. Psychiatry 162, 228-238.

Mataix-Cols, D., Nakatani, E., Micali, N., Heyman, I., 2008. Structure of obsessivecompulsive symptoms in pediatric OCD. J. Am. Acad. Child Adolesc. Psych. 47, 773-778.

Matsunaga, H., Maebayashi, K., Hayashida, K., Okino, K., Matsui, T., Iketani, T., Kiriike, N., Stein, D.J., 2008. Symptom structure in Japanese patients with obsessive-compulsive disorder. Am. J. Psychiatry 165, 251-253.

Nestadt, G., Samuels, J.F., Romanoski, A.J., Folstein, M.F., McHugh, P.R., 1994. Obsessions and compulsions in the community. Acta Psychiatr. Scand. 89, 219-224.

Research Triangle Institute, 2004. SUDAAN 9.0 User's Manual: Software for Statistical Analysis of Correlated Data. Research Triangle Institute, Research Triangle Park, NC.

Rufer, M., Grothusen, A., Mass, R., Peter, H., Hand, I., 2005. Temporal stability of symptom dimensions in adult patients with obsessive-compulsive disorder. J. Affect. Disord. 88, 99-102.

Ruscio, A.M., Stein, D.J., Chiu, W.T., Kessler, R.C., 2008. The epidemiology of obsessive-compulsive disorder in the National Comorbidity Survey Replication. Mol. Psychiatry. doi:10.1038/mp. 2008.94.
Samuels, J.F., Bienvenu, O.J., Grados, M.A., Cullen, B., Riddle, M.A., Liang, K.Y. Eaton, W.W., Nestadt, G., 2008. Prevalence and correlates of hoarding behavior in a community-based sample. Behav. Res. Ther. 46, 836-844.

Stein, M.B., Forde, D.R., Anderson, G., Walker, J.R., 1997. Obsessive-compulsive disorder in the community: an epidemiologic survey with clinical reappraisal. Am. J. Psychiatry 154, 1120-1126.

Stewart, S.E., Rosario, M.C., Baer, L., Carter, A.S., Brown, T.A., Scharf, J.M., Illmann, C., Leckman, J.F., Sukhodolsky, D., Katsovich, L., Rasmussen, S., Goodman, W., Delorme, R., Leboyer, M., Chabane, N., Jenike, M.A., Geller, D.A., Pauls, D.L., 2008. Four-factor structure of obsessive-compulsive disorder symptoms in children, adolescents, and adults. J. Am. Acad. Child Adolesc. Psych. 47, 763-772.

van den Heuvel, O.A., Remijnse, P.L., Mataix-Cols, D., Vrenken, H., Groenewegen, H.J., Uylings, H.B., van Balkom, A.J., Veltman, D.J., 2008. The major symptom dimensions of obsessive-compulsive disorder are mediated by partially distinct neural systems. Brain 132, 853-868. 